\title{
Psychological, Physical, and Social Health Needs of the Aging Society and Post-Pandemic Recommendations on Gerontology
}

\author{
Cathy Mae Dabi Toquero ${ }^{1 *}$
}

${ }^{1}$ College of Education, Mindanao State University, General Santos City, PHILIPPINES

*Corresponding Author: cathymaetoquero@gmail.com

Citation: Toquero, C. M. D. (2021). Psychological, Physical, and Social Health Needs of the Aging Society and Post-Pandemic Recommendations on Gerontology. European Journal of Environment and Public Health, 5(2), em0080. https://doi.org/10.21601/ejeph/11055

\section{ARTICLE INFO}

Received: 11 Mar. 2021

Accepted: 17 May 2021

\begin{abstract}
Older adults experienced the trepidation of COVID-19 as they are seriously the most affected in confirmed deaths. The aging population experienced the mayhem of health vulnerabilities and detrimental effects of the pandemic that aggravate their health issues. Consequently, the relentless call to meet the health needs of the older adults is inevitable. Hence, this article discusses the psychological, physical, and social needs of the elderly population amid a global health crisis. It introduces the significance of mattering for the aging society, stress on scientific-based physical activities, and concludes on the need for more research on gerontology in the postcoronavirus period. It also highlights that practitioners in the aging field need to circumvent discriminatory verbal or behavioral communication that may exacerbate ageism among the older adults. Policymakers, social workers, and medical practitioners should strengthen their efforts to prioritize geriatric health needs and expedite health interventions that can mitigate the impact of COVID-19 to the elderly.
\end{abstract}

Keywords: COVID-19, elderly health, health interventions, aging, ageism, social needs, psychological needs, physical needs, health needs, older adults

\section{INTRODUCTION}

As the pandemic took its toll on the elderly, they faced discrimination, anxiety, physical fatigue, and social withdrawal as a result of their age. Based on research, a healthy immune system is essential for dealing with health problems, so improving overall health is especially important, which can be accomplished through proper nutrition, physical activity, and coping strategies for mental health (Ranasinghe et al., 2020). During COVID-19, the benefits of exercise will help the elderly increase their immunity.

Similarly, a policy that is focused on the needs of the elderly will guarantee that their rights as older people are protected and that they are not neglected on provisions from the governments. The adoption of policies for older adults as a vulnerable group (Deusdad, 2020) will help them cope better with social distancing measures so their needs for social, physical, and psychological protection are addressed in institutional welfare programs or at their homes. Though COVID-19 complications have dealt a serious blow to older adults (Mills et al., 2020), immediate solutions are needed to mitigate COVID-19's negative health effects on the aging population.
Hence, this article contributes to the existing literature and future research in gerontology. This article deals with the psychological, physical, and social impact of COVID-19 to the elderly. It also emphasizes the need for practitioners and researchers concerned with gerontological issues to resist ageism in expression, writing, or actions, which can diminish the integrity of older adults and exacerbate their health problems in the midst of the pandemic.

\section{Significance of Mattering and Belongingness}

The need to show older people that they are respected and safe is especially important right now, since they are particularly vulnerable to the coronavirus's detrimental consequences. Since they are vulnerable to the negative effects of the coronavirus, such as anxiety, depression, and isolation, this sense of security and emotional fulfillment is absolutely critical during this time of social and physical isolation. Furthermore, it is evident that older adults need caring treatment that can improve their sense of well-being and belongingness in order to maximize the benefits of being valuable and cherished, as opposed to feelings of being expendable and disposable (Flett and Heisel, 2020). Flett and Heisel (2020) summarized research that suggests that mattering can lead to increased happiness among older adults to lower their levels of loneliness and depression. To sustain their social interaction and reduce the effects of isolation and 
loneliness, older people need family caregivers and other forms of assistance (Buenaventura, Ho, and Lapid, 2020). This mattering is then linked to the physical health of older adults to alleviate their tension and concerns about the crisis having an effect on their bodies.

\section{Cardiovascular Exercises and Physical Therapy}

COVID-19 prompted social isolation as a virus-prevention measure, which was accompanied by severe restrictions on outdoor activities. Since cardiovascular exercises and physical therapy are no longer available in gyms and fitness studios as a result of the closures, a reduction in everyday physical activities may occur, disproportionately affecting (Son et al., 2020) the elderly that can fuel metabolic complications (Schrack, Wanigatunga, and Juraschek, 2020). Physical inactivity is the fourth leading risk factor for global mortality (6 percent), followed by high blood pressure (13 percent) so older adults must engage in physical activities while at home or in nursing homes (WHO, 2009). On a global scale, it is estimated that over 5 million people die as a result of physical inactivity (Lee et al., 2012).

Physical activities that can be progressively increased in duration, frequency, and intensity are essential for older adults. Evidence indicates that physical activity has been linked to improved mental and physical functioning (WHO, 2010). The World Health Organization recommends that older adults aged 65 and up engage in moderate to vigorous intensity workouts, depending on their health conditions. Training older people for physical and mental fitness can be beneficial to them. When basic motor and cognitive functional skills are not used, the long-term negative effects can lead to total deterioration (Ehni and Wahl, 2020).

\section{Virtual Relations and Online Health Communications}

People worldwide rely on the virtual world or social media to connect to other people and maintain their social relationships during this crisis. The crisis is likely to alter the way older people experience aging as they need to go online for social relations. They need opportunities for social interaction and participation but which are currently restricted (Ehni and Wahl, 2020). Hence, the elderly people will need to make use of the digital platforms available so that they can also socialize with their friends and families through online communication. While many older people can have access to these platforms and devices to stay connected, it is vital to recognize that there are inequities to those who have access to technology and connectivity to foster social relationships (Henning-Smith, 2020).

While the older adults are not universally susceptible to COVID-19, nor are they the only victims, some older people face unique risks. For example, older adults located in rural settings have higher rates of some form of underlying health conditions, but they have limited access to health care and can experience volatile circumstances because of the COVID-19 (Henning-Smith, 2020). "Pre-existing rural/urban inequities related to health care capacity, economic security, access to technology, and social needs, together with within-rural inequities by socio-demographic characteristics together amount to heightened risk of illness and isolation for many older adults in rural areas” (Henning-Smith, 2020: 400).
Consequently, health communication measures and nontechnology reliant guidelines should also be taken into account as some older adults may not have advances in devices and online health communications due to connectivity issues, environmental settings, financial constraints, and technical limitations.

\section{RECOMMENDATIONS FOR ELDERLY HEALTH POST-PANDEMIC}

\section{Scientific-based Physical Programs}

Older adults experienced the effects of community lockdown as they cannot exercise outside of their homes. To keep their lifestyle from turning sedentary, they need to continue exercising through a home-based physical program. Evidence exists that regular physical activity and higher cardiovascular fitness among the elderly can show better responsiveness to vaccines but investigation remains to be seen for COVID-19 (Roschel, Artioli, and Gualano, 2020). Nevertheless, the authors pointed out that government agencies, universities, and professional healthcare task force should develop, experiment, and monitor scientific-based physical programs to increase the activity levels of older individuals.

\section{Familial Support and Volunteerism}

Of utmost importance for older people is the family support and encouragement to do physical exercises by being with them personally or virtually and giving them emotional support and value (Roschel et al., 2020). The older adults are also making use of online social relations to communicate with their friends and families. However, family members may need to assist the elderly as some of them may have difficulty with the complexities of modern technology. The interventions can include telephone calls with loved ones, friends, and voluntary organizations. In addition, the social digital leisure is also one way for older adults to combat isolation by creating a sense of community (Lizzo and Liechty, 2020; Nimrod, 2016; Son et al., 2020). Agencies or support groups can create volunteerism among older adults. As an example, older adults can utilize mobile phone calls for emotional support to those individuals who are in the most volatile households or they can also conduct leisure classes through online platforms (Son et al., 2020) so that the potential elderly volunteer can make use of their lifelong skills.

\section{Gerontological-friendly Policies}

The government needs to prioritize the welfare of older adults. Public policy goals should prioritize in nursing homes, as well as civic and local government-based support programs for community-dwelling older adults, to ensure that risk of infection is mitigated while promoting wellness during a period of stress and uncertainty (Mills et al., 2020). It is vital to store virus prevention items and 'no-touch technology' (Mills et al., 2020) that can provide protection for the workers in health care institutions to decrease transmission risks among older adults. Policies and future legal matters should consider the lens of the older adults to mitigate their vulnerabilities during an emergency. Ageism should be avoided to develop 
gerontological-friendly policies and reduce social exclusion of the aging society (Toquero, 2021).

\section{More Research in Gerontological Work}

There is a need to understand physically, socially, psychologically what is happening to older people. Özsungur (2020) also recommended that the psychological effects, psychological factors and aging should be investigated so that elderly people can better deal with the COVID-19 situation. Scientific inputs that produces "comprehensive, relevant, and appropriate mechanisms" may mitigate the difficulties of older adults (Cahapay, 2021: 15). Ehni and Wahl (2020) further stressed that the voluntary participation of the aging society in numerous gerontological studies provides basis that they support the investigations and testing conducted to them so long as researchers, medical professionals, and social workers uphold ethical standards for the conduct of the studies. "As human beings, older adults have the right to have the best research generated not only by virologists, but also by gerontologists to support their quality of life and prevent permanent damage" (Ehni and Wahl, 2020: 520). Ehni and Wahl (2020) further stressed that:

The participation of older adults in myriad gerontological studies proves that they have no problem when research is conducted with them, compared to when research is conducted on them, and they can always say no, as is the ethical standard. Then, of course, translation is necessary. As human beings, older adults have the right to have the best research generated not only by virologists, but also by gerontologists to support their quality of life and prevent permanent damage (Ehni and Wahl, 2020: 520).

Due to COVID-19, the insufficient knowledge on the mechanisms of immunity among the older population can still prevail, but when principles for effective community exist, then new strategies can be developed to control the disease that targets the older adults (Koff and Williams, 2020). Similarly, Reynolds (2020) concluded that the goal is a way forward and implement effective strategies to help the aging population. However, she also argued that researchers or practitioners in the discipline of gerontology need to educate themselves to restrain from committing ageism messages whether in speech, writing and behavior. It is pertinent that ageism or other forms of discrimination towards the elderly should be avoided

in curriculum, articles, classrooms, housing, long-term support and service settings, and government agencies. Advocacy efforts must be accomplished without inadvertently contributing to ageism, and efforts to renegotiate and revise social policies and implement initiatives to address and prevent ageism must become a priority (Reynolds, 2020: 504).

\section{CONCLUSION}

COVID-19 exposed the vulnerabilities of older adults as this age group dealt with the most confirmed deaths. Older adults suffer from the detrimental impact of COVID-19 whether psychologically, physically, and socially. As a result, the need of the elderly for psychological safety, physical functioning, and social protection should be met amid the pandemic and in the post-pandemic period. The older people need to feel the sense of well-being and belongingness to fulfill their psychological needs amid extreme community quarantine and social distancing protocols. Scientificallyproven and age-appropriate exercise recommendations can mitigate for their need for physical activities while staying safe at home. Likewise, the importance of social support to fulfill their social needs is possible through online social relations and utilizing what technology can offer amid this crisis. This article offers social, practical, and policy implications to ameliorate the conditions of the elderly people. Socially, older adults can make use of digital technologies to build social relationships among their networks and make use of their acquired lifelong skills to help other elderly. Through telemedicine and similar technologies, the impact of COVID19 can be mitigated as the provision of healthcare needs using different methods of digital platforms can be used to help the elderly. This article also recommends some proposed strategies and probable solutions to lessen the social, physical, and psychological impact of the pandemic to the health of the older adults. Thus, of critical importance is for national policymakers and health practitioners to reinforce assistance for the older adults amid home quarantine and social distancing measures. Governments, agencies, and health institutions should prioritize and address the social needs and psychological support of older adults for emotional resilience and sense of well-being to rid anxiety and other negative effects of COVID-19. Policies and laws can be promulgated that have an elderly-based lens to also consider the welfare of older people as they are more susceptible to any future outbreaks. Thus, recovery health planning of the governments, agencies, and health institutions can address the health inequalities and inequities that detriment the older people in post-pandemic. More research is needed in the field of aging studies such as an investigation of the psychological effects of COVID-19, development of strategies for immunity and control of the COVID-19 among the elderly, and the prevention of ageism practices to protect the aging society.

Funding: No external funding is received for this article.

Declaration of interest: Author declares no competing interests. Ethics approval and consent to participate: Not applicable.

Availability of data and materials: All data generated or analyzed during this study are available for sharing when appropriate request is directed to the author.

\section{REFERENCES}

Buenaventura, R. D., Ho, J. B. and Lapid, M. I. (2020). COVID19 and mental health of older adults in the Philippines: a perspective from a developing country. International Psychogeriatrics, 32(10), 1129-1133. https://doi.org/ 10.1017/S1041610220000757 
Cahapay, M. (2021). Senior citizens during COVID-19 crisis in the Philippines: Enabling laws, current issues, and shared efforts. Research on Ageing and Social Policy, 9(1), 1-25. http://doi.org/10.4471/rasp.2021.6066

Deusdad, B. (2020). COVID-19 y la Crisis de las Residencias de Mayores en España: Edadismo y Precariedad [COVID-19 and the Crisis of Residences for the Elderly in Spain: Ageism and Precariousness]. Research on Ageing and Social Policy, 8(2), 142-168. http://10.4471/rasp.2020.5598

Ehni, H. J. and Wahl, H. W. (2020). Six propositions against ageism in the COVID-19 pandemic. Journal of Aging \& Social Policy, 32(4-5), 515-525. https://doi.org/10.1080/ 08959420.2020 .1770032

Flett, G. and Heisel, M. (2020). Aging and feeling valued versus expendable during the COVID-19 pandemic and beyond: A review and commentary of why mattering Is fundamental to the health and well-being of older adults. International Journal of Mental Health and Addiction. https://doi.org/10.1007/s11469-020-00339-4

Henning-Smith, C. (2020). The Unique Impact of COVID-19 on Older Adults in Rural Areas. Journal of Aging \& Social Policy, 32(4-5), 396-402. https://doi.org/10.1080/08959420.2020. 1770036

Koff, W. and Williams, M. (2020). Covid-19 and immunity in aging populations - A new research agenda. The New England Journal of Medicine, 383, 804-805. https://doi.org/10.1056/NEJMp2006761

Lee, I., Shiroma, E. J., Lobelo, F., Puska, P., Blair, S. N. and Katzamarzyk, P. T. (2012). Impact of physical inactivity on the world's major non-communicable diseases. Lancet, 380, 219-229.

Lizzo, R. and Liechty, T. (2020). The Hogwarts Running Club and sense of community: A netnography of a virtual community. Leisure Sciences. https://doi.org/10.1080/ 01490400.2020.1755751

Mills, J., Kaye, K. and Mody, L. (2020). COVID-19 in older adults: clinical, psychosocial, and public health considerations. JCI Insight, 5(10), e139292. https://doi.org/ 10.1172/jci.insight.139292
Nimrod, G. (2016). Online self-management of well-being in later life. Interdisciplinary Studies on the Family, 28, 247262.

Özsungur, F. (2020). COVID-19: A perceptual approach to aging: Latent aging. Research on Ageing and Social Policy, 8(2), 169-191. http://10.4471/rasp.2020.4836

Ranasinghe, C., Ozemek, C. \& Arena, R. (2020): Exercise and well-being during COVID 19 - time to boost your immunity. Expert Review of Anti-infective Therapy, 18(12), 1195-1200.

https://doi.org/10.1080/14787210.2020.1794818

Reynolds, L. (2020). The COVID-19 pandemic exposes limited understanding of ageism. Journal of Aging \& Social Policy, 32(4-5), 499-505. https://doi.org/10.1080/08959420.2020. 1772003

Roschel, H., Artioli, G. and Gualano, B. (2020). Risk of Increased Physical Inactivity During COVID-19 Outbreak in Older People: A Call for Actions. JAGS, 68(6), 1126-1128. https://doi.org/10.1111/jgs.16550

Schrack, J., Wanigatunga, A. and Juraschek, S. (2020). After the COVID-19 pandemic: The next wave of health challenges for older adults. The Journals of Gerontology: Series A, 75(9), e121-e122. https://doi.org/10.1093/gerona/glaa102

Son, J., Nimrod, G., West, S., Janke, M., Liechty, T. and Naar, J. (2020). Promoting older adults' physical activity and social well-being during COVID-19. Leisure Sciences, 43(1-2), 287-294. https://doi.org/10.1080/01490400.2020.1774015

Toquero, C. M. D. (2021). Geriatric Health in an Unprecedented Global Emergency and Strategies to Alleviate the Impact of COVID-19. Revista Universitaria De Sociologie, 17(1), 9-16. http://www.sociologiecraiova.ro/revista/wpcontent/uploads/2021/04/RUS-1_2021_ff-9-16.pdf

World Health Organization (WHO, 2009). Global health risks: Mortality and burden of disease attributable to selected major risks.

World Health Organization (WHO, 2010). Global recommendations on physical activity for health. 